\title{
TRANSPORTATION PROJECT EVALUATION IN VIETNAM
}

\author{
Toshikazu SHIMAZAKI* and PHAN NGOC THACH**
}

\begin{abstract}
A pay-back period method used for transportation project evaluation in Vietnam is characterized by some principal disadvantages and may result in an incorrect rank of alternatives and subsequently in irrational decision making. Despite of these, it may be used, after some modification, as rough evaluation means. Under recent economic reform, standard evaluation methods have started to be used. It faces a lot of issues. An attempt is given in this research to introduce some appropriate techniques to overcome these issues.

Key Words : Project evaluation, pay-back period, standard methods, central planning, free market.
\end{abstract}

\section{INTRODUCTION}

In 1986, in order to improve critical situation of the economy, it was strategically decided to introduce economic reforms in Vietnam to transfer the national economy from the centrally-planned to free-market mechanism. Since then, a number of market economy-oriented changes has been implemented in many areas such as pricing, revenue and expenditure, exchange rate and foreign investment. As an initial result, some improvements have been recognized in the national economy. These include significant decrease of government subsidies to state-owned enterprises, gradual weakening of price control by the government, increase of the financial autonomy of state-owned enterprises, booming expansion of private enterprises creating significant competition among different economic sectors, and introduction of a new and more liberal Foreign Investment $\mathrm{Law}^{1}$.

The economic reforms have led to sound changes in transportation system of the country also. These changes have involved both physical characteristics of the transportation network as well as operation of transportation organizations. Generally, the economic development requires a strong support from transportation infrastructure. In reality, however, the present state of transportation facilities of Vietnam is not in the case to meet this important requirement. It has been recognized that existing transportation

* D. Eng., Associate Professor, Dept. of Civil Engineering, Faculty of Engineering, University of Tokyo; Formerly, Division of Geotechnical and Transportatio Engineering Asian Institute of Technology.

** M. Eng., Research Associate, Division of Human Settlement Development, Asian Institute of Technology. facilities are inadequate to handle growing traffic volumes, and the poor performance of this sector seems to hold back the economic development ${ }^{2}$. There are a lot of reasons behind the low level of transport development. They mainly include a severe lack of resources for construction, maintenance and development of transport infrastructure and failed transportation planning scheme under the centrallyplanned system of economy in the past, which puts significant emphasis on implementation of big new projects rather than maintenance and effective use of existing assets.

The recent economic reforms have required an immediate solution of these problems. In regard to the first problem, the government has been looking for investment capital from different sources. In order to obtain this objective, the Vietnam's government has introduced new Foreign Investment Law to promote foreign investment and copartnership policies between central and local government or between government and local people to promote domestic investment. Up to 31 January 1992, 34 foreign investment projects in transportation and communication with total invested capital of US $\$ 233,400,00$ have been approved ${ }^{3)}$. It is more difficult to deal with the second problem because this involves the complex project evaluation scheme. Only a proper project evaluation can enable decisionmakers to make correct selection of optimum alternative project among a large amount of possible options. This process appears to be particularly important for poor developing countries, where the total available resources are limited and there are competing demands from various economic sectors.

The main purpose of this paper is to propose 


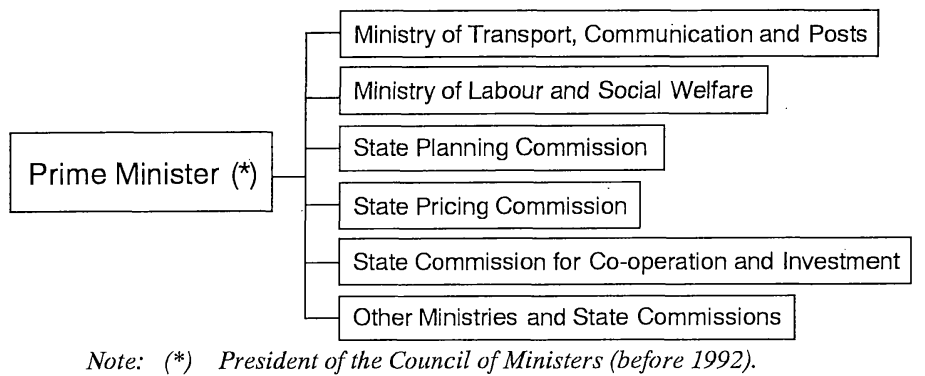

Fig. 1 Administrative Structure of Central Government Relating to Transportation Projects

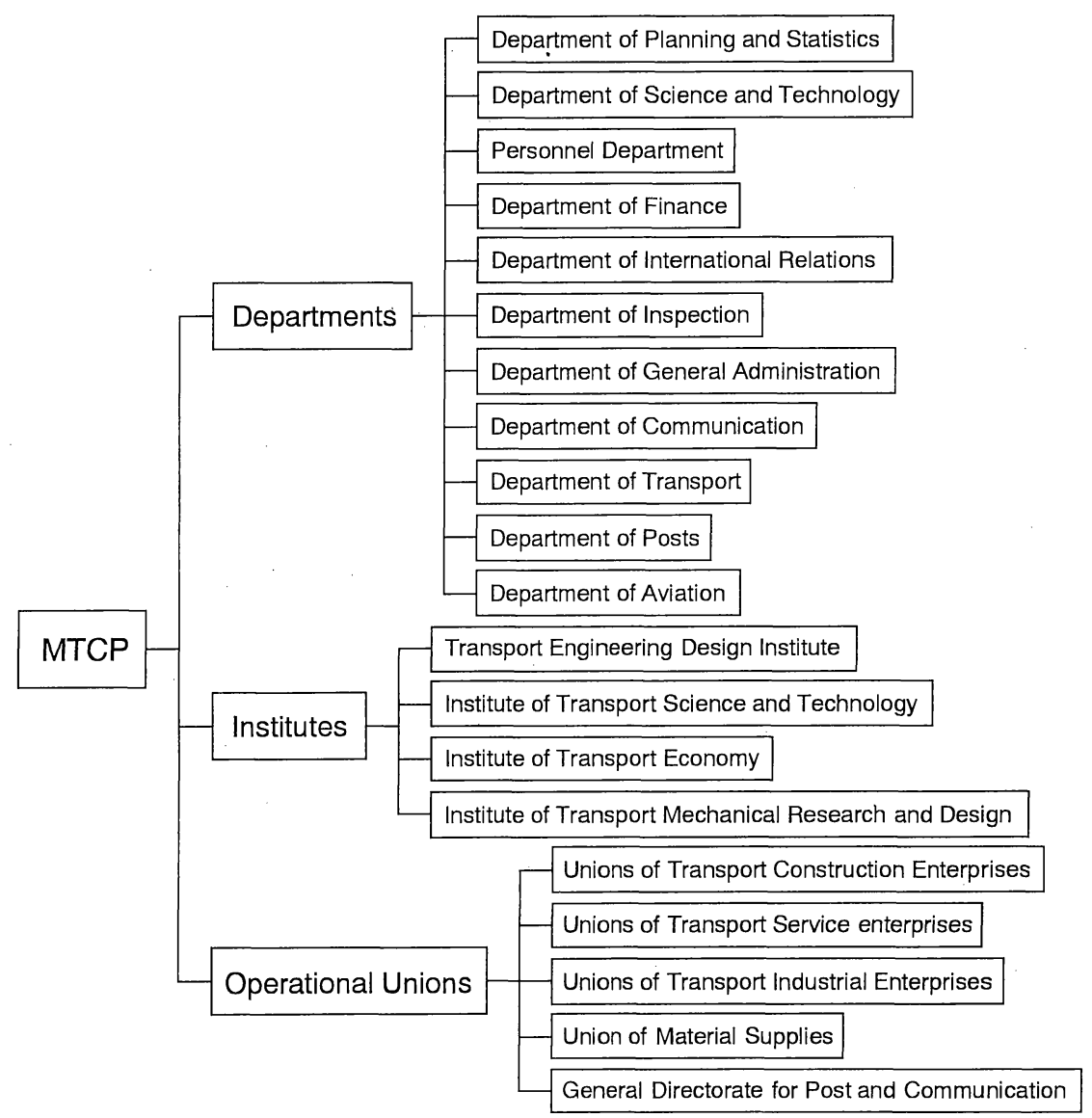

Fig. 2 Administrative Structure of Ministry of Transport, Communication and Posts (MTCP) (After Reorganizing in 1990)

appropriate techniques for improvement of transportation project evaluation process under the recent economic reforms in Vietnam, which is the typical example of economic system change. The paper aims to review a procedure of transportation project execution in Vietnam, to analyze advantages and disadvantages of existing economic evaluation method used for transportation projects in Vietnam and issues of its performance under recent economic reforms, and to propose appropriate techniques to improve the economic evaluation of transportation projects in Vietnam as a typical example.

Until 1990, an operation of the Civil Aviation in Vietnam is managed by the General Civil Aviation Administration. It was a state agency independent from the Ministry of Transportation, Communication and Post (MTCP). Therefore, issues discussed in this paper are concerned with only roads, railways 
and waterways, operation of which is under management of the MTCP. At present, an administrative structure of the Central Government and MTCP are illustrated in Fig.1 and Fig.2, respectively.

\section{PAST PROJECT EXECUTION IN VIETNAM}

Under the centrally-planned mechanism of economy the investment system was highly centralized. This centralism appeared in every stage of a project execution process: identification, formulation, design, evaluation, funding, and implementation.

\section{(1) Project Identification and Formulation}

In transportation, the project identification was mainly undertaken based on 3 sources: directional plans, feasibility studies and reports about real performance of transportation facilities.

There are two kinds of directional plans: mediumterm and long-term. Both of them are made by Institute of Transport Economy based on transport demand projections. The effectiveness of transportation plan requires an adequate planning methods, availability of statistical data concerning the operation and performance of individual transportation modes in the past, proper forecast of the economic growth rate and population growth rate. In the current medium-term plan for 1986-1995 and long-term plan for 1986-2005, this requirements were not satisfied. Firstly, the planning process was not based on a macroeconomic approach through which transport demands can be properly identified ${ }^{4)}$. In addition, the intermodal analyses were not undertaken and the planning in a certain mode was performed without particular consideration of other modes. Secondly, there is an obvious lack of necessary statistical data. In the past, information and data related to the physical utilization and productivities of transport facilities as well as performance and operation of transportation modes were classified as confidential. This had caused a lot of difficulties for planners to obtain true data. And finally, there is a considerable uncertainty about economic development level and population growth when looking for 10-20 years ahead, particularly during the economically instable period. For instance, the medium-term plan for 1986-1995 was based on an annual overall economic growth rate of $4 \%{ }^{2)}$ and the planners could not foresee an economic decline with overall growth rate of $2.1 \%$ in 1989.

In recent years, feacibility studies have been
Table 1 Some Design Standards of Highways

\begin{tabular}{|l|c|c|c|c|c|}
\hline & \multicolumn{5}{|c|}{ Highway Category } \\
\cline { 2 - 6 } & 1 & 2 & 3 & 4 & 5 \\
\hline Number of Lanes & 4 & 2 & 2 & 2 & 2 \\
Lane Width, m & 3.75 & 3.75 & 3.50 & 3.50 & 3.50 \\
Shoulder Width, m & 3.00 & 2.50 & 1.50 & 1.50 & 1.50 \\
\hline
\end{tabular}

Note: Categories 3, 4 and 5 differ in some technical papameters such as minimum radius of curves, maximum gradient, etc.

performed by the Transport Engineering Design Institute (TEDI) to identify transportation project possibilities. The feasibility studies put an emphasis on the technical and financial requirements and consequences of the proposed projects.

The Unions of Transport Construction Enterprises, who are in charge of management of roads, railways and waterways, submit periodical reports to the involved Technical Departments of the MTCP. In these reports, the operation and performance of transport facilities are mentioned. They also contain level of transport facility deterioration, particularly when and/or where a deterioration reaches critical condition.

Based on directional plans by Institute of Transport Economy, feasibility studies by Trasnport Engineering Design Institute and periodical reports by Unions of Transport Construction Enterprises, the Department for Planning and Statistics formulated transportation project proposals. The project proposals contain a conception of the project scale, its objectives, the nature of its benefits. Then the project proposals were reviewed by the State Planning Commission. These reviews may require additional information from the project proposers as well as relevant sections of the State Planning Commission itself. If the project is approved, the project then becomes a candidate for inclusion in the investment programme of the Government.

\section{(2) Project Design and Evaluation}

Transportation projects accepted as candidates require a further design. This is usually performed by the TEDI. But sometimes it is given to provincial transport design institutions, particularly small projects such as maintenance or rehabilitation of existing road transport facilities or construction of low-cagetory highways which are not beyond the technical possibilities of these institutions. Transport 
facilities are designed according to current Vietnamese standards related to particular transport modes. In the case of highways, for example, the standards TCVN 4045-85 are used according to the proposed category of highways (see Table 1).

It is important to note that, despite of available standards, some geometric parameters of transport facilities are chosen arbitararily by high-level individuals without any rational basis. This phenomenon seems to happen more often with number of lanes and their width, maximum longitudinal gradient and minimum radius of highways, but seldom in the case of railways and waterways.

Once the transportation project has been fully designed, it needs to be appraised before inclusion in a prospective project process. Transportation project appraisals are usually carried out by the designers themselves: the TEDI or sometimes provincial transport design institutions.

In the centrally-planned economy, the government agencies placed an emphasis on financial suitability of projects. Therefore, most transportation project analyses were concentrated to financial appraisal. The financial appraisal has been made in official prices. It is important to note that a majority of goods and services were price-controlled with significant subsidies by the Government. As a result, the official prices were usually much lower than market prices and these official prices understated the effective costs of goods and services. Only for some large transportation projects financed by foreign governments or international agencies, an economic appraisal was performed to review whether investment will be effective to the economy. For this purpose, an elementary pay-back period method was used.

Only in recent years, standard methods of economic appraisal proposed by international agencies like World Bank (WB), Organization of Economic Cooperation and Development (OECD) and United Nations DevelopmentProgramme (UNDP) has been introduced to Vietnam. In transportation, for example, in 1991 the Highway Design and Maintenance model (HDM-III) proposed by the World Bank was firstly applied to analyze the Hanoi-Vinh highway rehabilitation project ${ }^{5}$. However, because of limited time and shortage of data, only vehicle operating cost reduction was considered as project benefit. The other aspects of projects appraisal such as insti-tutional, commercial, social and environmental, appeared not to be taken.
After appraisal, transportation projects need to be approved, firstly by the MTCP and finally by the State Planning Commission. Under a centrallyplanned system, the State Planning Commission was the central agency with the responsibility for coordinating the economic activities of the Government. This involved the Five-Year and Annual Plans for the whole national economy as well as for each ministry and government agency within the economy. This powerful State Planning Commission set physical output targets for activities of ministries and agencies. This role has changed considerably following the economic reforms: it is now responsible for planning of Government's expenditures and for compiling of the public sector investments and capital work programmes ${ }^{2}$. The State Planning Commissin now advises the Central Government on selection of projects for inclusion in the Government's programme.

Recently, transportation projects invested by foreign companies or international agencies are formulated and analyzed by the State Commission for Co-operation and Investment through its National Centre for Project Evaluation.

\section{(3) Project Funding and Implementation}

Candidate projects which are included in the Government's investment programme proceed to implementation stage. The implementation of transportation projects are financed from the Government's investment fund or foreign investment fund through banks. In transportation, construction and maintenance of transport facilities are carried out by Unions of Transport Construction Enterprises. The project implementation is carried out under the technical supervision of the TEDI or other transport design agencies and financial monitoring of the bank, through which project is funded. These supervision and monitoring are needed to ensure that transportation projects are proceeding as designed and approved.

The transportation project implementation capacity of the Unions is practically very poor because of the lack of finance and inadequate construction or maintenance technology. A main portion of the construction and maintenance equipment fleet is obsolete with low productivity. In many cases, spare parts for such obsolete equipment are very scarce because foreign manufacturers have stopped producing them a long time ago. In order to overcome this issue, some spare parts are produced by domestic manufacturers or are supplied by special order from foreign manufacturers. Despite of these 
efforts, only 1507 among 3140 units (48\%) of maintenance equipment fleet of the MTCP are operative ${ }^{2)}$. In this circumstance, severe construction and maintenance works are performed manually.

\section{PROJECT EVALUATION METHOD IN VIETMAN}

\section{(1) Pay-back Period Method Used in Vietnam}

In the centrally planned economy, the pay-back period method was used in Vietnam for evaluation of transportation projects. The pay-back period is defined as a number of years which must elapse following the commencement of projects, before all construction costs are recovered. The pay-back period can be defined as follows:

$$
T=\frac{C}{\left(K^{\prime}-K\right)+\left(M^{\prime}-M\right)}
$$

Where

$T$ - Pay-back period, years,

$C$ - Construction cost, millions dong,

$K, K^{\prime}$ - Undiscounted vehicle operating cost in the middle of the project life with and without project, respectively, millions dong/year,

$M, M^{\prime}$ - Undiscounted maintenance cost in the middle of the project life with and without project, respectively, millions dong/year.

If pay-back period is less than project life, project is considered to be economically justified.

The main advantage of the pay-back period method of economic evaluation for transportation projects is that it allows the planners to avoid the difficulties in identification of discount rate. However, this method has many disadvantages and does not always gives a sound project justification and proper project ranking. These disadvantages are as follows:

(i) Because all cost and benefits are not discounted, the pay-back period method fails to consider time value of money.

(ii) The pay-back period determined by the formula (1) fails to consider the benefits from travel time savings, accident cost savings and economic development benefits etc. It is expected to be significant misestimation of project benefits in the case of new construction or high time value of passengers.

(iii) In formula (1), the benefits in the middle of the project life are assumed as average annual benefits. So, it fails to consider the difference in benefits at different time during project life length.

(iv) The pay-back period method fails to consider benefits properly when benefits fluctuate. This failure may result in followings:

- Incorrect rank of projects. If one project may pay back in shorter period of time but produce no benefits after that, while another project with longer pay-back period may continue to give benefits after pay-back period. The pay-back period method would rank the first project ahead of the second one, while the net present value method may rank the second project ahead of the first one due to long-run benefits. So, in transportation the pay-back period method gives superiority to maintenance project with small capital cost, short life length because this kind of projects usually has shorter pay-back period than large projects with completely new or reconstruction of transportation facilities.

- Penalization of investment project with initial negative benefit, although the long-term benefits from such projects may be very high.

(v) In the case of stage investment, projects may have multiple pay-back period.

Because of these disadvantages, the pay-back period are not used in practice of economic evaluation of transportation projects in the free market economy. STOPHER and MEYBURG have not included pay-back period in criteria for transportation project evaluation ${ }^{6}$. BUTTON and PERMAN consider that the longevity and high costs of most major pieces of transport infrastructure make elementary pay-back period method cease to be of any real use ${ }^{7}$. DICKEY and MILLER consider payback period as a rough means of choosing between investments in business enterprises, especially where there is a high degree of risk. In transportation projects, however, it is not a common measure because there is comparatively little risk of technological obsolescence ${ }^{8)}$.

\section{(2) Estimation of Cost of Goods}

Economic evaluation of transportation projects entails the measurement and comparison of costs and benefits expected from alternative investments. This involves an estimating a cost of many goods such as construction materials and machinery, fuel and lubricating oil, tires, spare parts, and vehicles.

In the centrally planned economy, it was very difficult to estimate the economic costs of goods because:

(i) The government policy of price control distorted a real monetary value of goods. For most goods there was a complex set of prices varying by various degrees of government control: prices set by the government, prices negotiated by enterprises, socalled internal prices determined inside certain 
enterprise and market prices.

(ii) There were several exchange rates and the disparity among them was very great ${ }^{9)}$. They included the official rate, the non-merchant rate in settlements with the Council for Mutual Economic Assistance (CMEA), the so-called internal accounting rate between the Bank of Foreign Trade and the import-export organizations, the incentive rate for overseas Vietnameses and the market rate.

(iii) The information and data related to the level of government subsidies and degree of price control were classified as confidential. Usually, the transportation planners could not get these data. Only in a few cases, they were provided after approvement of high-level officials but they might be modified for political reasons.

(iv) For imported goods, there was an additional complication concerns trade under bilateral trade agreements between member-countries of the CMEA. The value of earnings from such trade was still only notional, because there was an obligation on both sides to balance. If balance was not achieved, pressures will be used when the next agreement is negotiated. In these circumstances, FOB and CIF estimated in the bilateral trade agreements did not correctly reflect the shadow prices of traded goods. Generally, these prices underestimated the economic value of traded goods.

In these circumstances, economic evaluation of transportation projects were based upon the official prices determined by the State Pricing Commission. These official prices generally underestimated the effective cost of goods.

\section{(3) Estimation of Labour Cost}

In the past, in most economic evaluations of transportation projects the labour cost was estimated at actual money wage of labour in government sector. For example, in the economic screening of national highway No. 1 improvement project, the TEDI estimated labour cost at Dong 150,000/month (US $\$ 17 /$ month $)^{5}$. It appeared to underestimate economic cost of labour because under centrally planned economic mechanism, besides the actual money wage, the labour received an additional income. It covered the possibility of buying rationed goods at subsidized prices and social welfare benefits. Rationed goods included basic consumer commodities, which could be purchased at quantities and qualities which varied in accordance with bureaucratic position. The social welfare benefits included subsidized housing, health, transportation, and other public utility facilities. In addition, contributions for pensions and social security were minimal, as most of these expenditures were financed by the national budget. This additional income was difficult to estimate since the concerning statistics were not opened for public use. Moreover, they seemed to be of vary different nature affected by socio-economic factors. For example, labours in rural areas or remote towns usually had fewer opportunities to buy all rationed goods at subsidized prices than their colleagues in big cities simply because of unavailability of these goods. In addition, the social welfare facilities in rural areas were usually worse than in cities. So, labours in cities might receive more additional income more than their colleagues in rural areas do.

The wage of Dong 150,000/month alone seemed to be underestimated even for cost of unskilled labour. It could not rationally reflect cost of transferring unskilled labours out of the rural sector.

The other problem of government wage system under centrally planned economy of Vietnam in the past was egalitarian principles. These principles distorted the different outputs foregone by skilled and unskilled labour. Sometimes unskilled labour received the same or even higher salary than skilled labour did. For example, in state institutions it was quite often that young engineer's salary was lower than salary of janitor who had worked for long time.

\section{IMPROVEMENT OF EVALUATION METHOD}

\section{(1) Proposal of Evaluation Method}

It would appear that there is considerable gap between project evaluation techniques used in Vietnam and those acceptable to international institutions. The economic reform from centrally planned to free market mechanism has required a change in the methodology of economic evaluation for transportation projects. The same conclusion was reached by UNDP economists ${ }^{2)}$ : "There is a need to introduce new and more systematic appraisal methods than have been used in the past, in order to improve the internal system of resource allocation. In addition, of course, a very practical reason for the increasing use of project appraisal techniques is that many funding agencies will expect projects to be appraised according to standard methods".

Generally, there are 3 standard methods of project appraisals using 3 different criteria: Net Present Value (NPV), Internal Rate of Return (IRR) and Benefit-Cost Ratio (BCR). It is pointed out by several authors that among these standard methods, net 
present value is the best means for economic evaluation of transportation projects and is used in most cases ${ }^{6,7), 88,10)}$. It is proposed to use for economic evaluation of transportation projects in Vietnam to replace the pay-back period method.

(2) Modification and Usage of Pay-back Period

The standard method of economic evaluation generally requires a lot of time and resources to collect and analyze data, particularly when there are many possible alternatives. It appears that if the pay-back period method can be improved by eliminating or minimizing its disadvantages, it seems to be useful for transportation planners to reduce a number of alternatives. The use of pay-back period method as a rough selection means can save time and resources spent for economic evaluation of projects in the country where the infrastructure developments are urgent. In order to do so, following modifications are possible:

(i) Replace undiscounted costs and benefits by present value of costs and present value of benefits, respectively;

(ii) Include as far as possible all tangible items of project benefits such as travel time savings, traffic accident savings and economic development promotion of projects;

(iii) Determine pay-back period as the time period such that:

$$
\sum_{t=0}^{T} \frac{B_{t}-C_{t}}{(1+i)^{t}}=0
$$

Where

$T$ - Pay-back period, years

$B_{t}$ - Project benefit in year $\mathrm{t}$

$C_{t}$ - Project cost in year $\mathrm{t}$

$i$ - Discount rate.

The procedure of project choice among large number of alternatives is proposed as follows:

(i) To divide possible alternatives into some groups by physical alterations (new construction projects, reconstruction projects and maintenance projects) so that investment size and life length of projects inside the same group vary a little each from other. By this we can reduce incorrect rank of projects by the pay-back period method.

(ii) To use the pay-back period method to rank alternatives inside each group and to choose the best alternative to represent the certain group in a final selection.

(iii) To use the standard method to rank the representatives of groups and to make a final selection.
This proposed usage of the pay-back period method of economic evaluation is useful, particularly during the present period of transferring from centrally planned to free market economy when still only a few planners can understand the meanings of net present value and they are too familiar with the pay-back period method after a long time of its use.

\section{(3) Method to Overcome the Lack of Data}

\section{a) Lack of Data on Cost of Goods}

Generally, in the free market economy, CIF prices are used to estimate cost of imported goods. If for some reasons the data about CIF prices of certain imported goods are missing, the planners then may use the CIF prices of the same goods in the other country if Vietnam and this other country import this kind of goods from the same source, and Vietnam and this other country are located in similar distance by ship from a source of goods. In 1991, for example, the TEDI used CIF price of bitumen in Sulawesi island (Indonesia) to estimate economic cost of pavement overlay in the National Highway No. 1 improvement project. Sulawesi is a similar distance by ship from Singapore withthe project location in Vietnam.

b) Lack of Data on Labour Cost

Generally, agricultural productivity etc. are used for shadow wage rate in the free market economy. It is not, however, adequate in Vietnam, because of restriction on moving of farmer and so on. The wage of labour in private sector is expected more appropriate than in government sector to represent opportunity cost of labour in Vietnam during stage of economic reform, because there is no government subsidies and no impact of wage egalitarian principles in private sector.

In 1991, a small survey was performed to determined cost of skilled and unskilled labour in private sector in Vietnam ${ }^{11}$. According to a result of the survey, the average wage rate is of US $\$ 60$ and $40 /$ month for skilled and unskilled labour respectively. This result has been confirmed latter by two different sources. Firstly, in 1990, Ministry of Labour and Social Welfare (MLSW) fixed a minimum wage of US $\$ 50$ /month for Vietnamese labour in joint ventures. However, almost all foreign investors agreed that the minimum wage of US \$ $50 /$ month was high, especially when there are a great number of unskilled labours ${ }^{12}$. That is why in May 1992, the MLSW reduced a minimum wage of labour to US \$35/month for Hanoi and Ho Chi Minh city and US \$30/month - for other cities and provinces. Secondly, in 1992, in order to propose investment 
in Vietnam, a group of Taiwanese businessmen performed study about investment opportunities in Vietnam. According to the result of this study the opportunity cost of unskilled labour in the country can be ranged US\$ 30 to US \$40/month.

c) Lack of Needed Research Studies

In an economic evaluation of transportation projects, it is necessary to use results of research studies to determine the complex relationship between different cost and benefit items and physical characteristics of transportation facilities. Unfortunately, as in the first stage of standard method use, most these research studies have not been performed yet in Vietnam. However, such research studies have been carried out in a number of countries with different natural conditions and different socioeconomic natures. The results of these research studies incorporated in different computer models of economic evaluation of transportation projects, such as HDM-III developed by the World Bank and RTIM-2 developed by the Transport and Road Research Laboratory (United Kingdom). In order to use these models, it is necessary to calibrate the results according to local conditions regarding a number ofspecific aspects such as the climate factors, the characteristics of vehicle fleet and so on. For the time being, it will be required to use interpolation or extrapolation to find model parameters, if possible. Sometimes the same technique is performed to use results of the models themselves.

\section{CONCLUSION}

The pay-back period method, used in Vietnam in the past, is simple in both concept and calculation. It has been familiar both for planners and decision makers in the centrally planned economy. Because of its principal disadvantages, it is necessary to substitute it by standard methods in order to choose the most rational decision for investment in condition of free market economy. However, after some modifications it can be used as a rough selection means to reduce a number of alternatives entering in economic evaluation. The use of the standard method of economic evaluation has just been started. More refinements are required in order to establish an elaborate procedure of economic evaluation of transportation projects in Vietnam, where the economic system is changing. Research studies in all aspects are needed to fill the gap in project evaluation process now.

\section{REFERENCES}

1) Government of Vietnam: Law on ForeignInvestment in Vietnam, 1987.

2) United Nations Development Program: Report on the Economy of Vietnam. United Nations, 1990.

3) Bangkok Post, 7 July 1992.

4) Japanese International CooperationAgency:Development and Management Profile of Transport Infrastructure in Asia and the Pacific (Supplement). Institute for International Cooperation, 1991.

5) Transport Engineering Design Institute: Design Report for the Hanoi-Vinh Highway Improvement, 1991.

6) Stopher P.R.\& Meyburg A.H.: Transportation System Evaluation. Lexington Books, 1978.

7) Button K.J. \& Pearman A.D.: The Practice of Transport Improvement Appraisal. Rober Hartnoll Ltd., 1983.

8) Dickey J.W. \& Miller L.H.: Road Project Appraisal for Developing Countries. John Wiley and Sons, 1984.

9) Nguyen Huu Dong: China, Vietnam: Chronicle of Announced Reforms. Journal of Development Planning No. 20, Department of International Economic and Social Affairs, United Nations, 1990.

10) Transport and Road Research Laboratory: Overseas RoadNote 5: A Guide to Road Project Appraisal, 1988.

11) Phan Ngoc Thach: Economic Appraisal of Transportation Projects in Vietnam through a Case Study on the Improvement of National Highway No. 1. AIT Master Thesis, 1992.

12) Vietnam Investment Review, 23-29 December 1991.

(Received April 19, 1993)

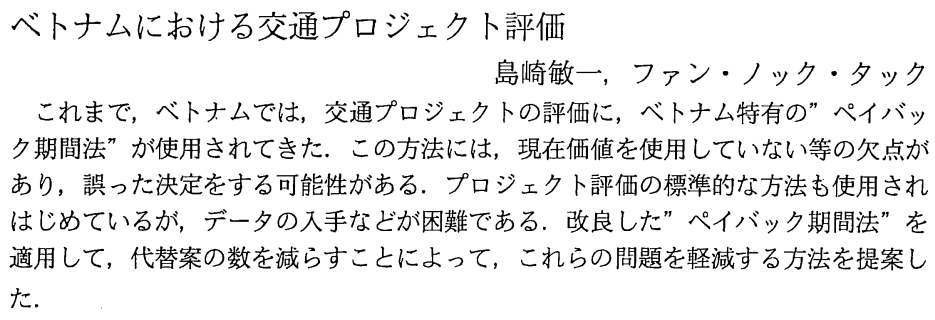

